\title{
PELANGGARAN MAKSIM (FLOUTING MAXIM) DALAM TUTURAN TOKOH FILM RADIO GALAU FM: SEBUAH KAJIAN PRAGMATIK
}

\author{
Niswatin Nurul Hidayati \\ STAI Al Hikmah Tuban \\ Email: niswatinnh@gmail.com
}

\begin{abstract}
The cooperative principle proposed by Grice stated "make your contribution such as is required, at the stage at which it occurs, by the accepted purpose or direction of the talk exchange in which you are engaged", but in the real life communication, this principle was often being flouted which was known as flouting maxim. This research aimed to describe the flouting maxim phenomenon in one of Indonesian films, Radio Galau FM.From the analysis of the collected data, the researcher found that some conversation of the main characters in this movie contained flouting maxim, whether it is flouting maxim of quantity, quality, relevance, and also manner. When the flouting maxim happened, it contained certain implicature, in which the speaker intended to deliver certain implicit message, such as assuring the hearer, giving surprise, asking for attention, also avoiding the conflict".
\end{abstract}

Keywords: cooperative principle, flouting maxim, implicature, film

\section{A. Pendahuluan}

Bahasa merupakan bagian yang tidak terpisahkan dari kehidupan manusia karena fungsinya sebagai alat komunikasi. Proses berkomunikasi dapat dilakukansecara terulis maupun lisan. Terdapat perbedaan antara penggunaan bahasa tertulis dan bahasa ujaran, ketika seseorang menggunakan bahasa tertulis maka bahasa yang digunakan berada dalam format yang formal dan sangat memperhatikan tata bahasa yang digunakan, sedangkan ketika bahasa ujaran digunakan, pembicara cenderung lebih memperhatikan bagaimana agar isi dari ujaran tersampaikan dengan baik daripada memperhatikan tata bahasa dari ujaran yang dihasilkan.

Di dalam suatu komunikasi, penutur akan menyampaikan pesan tertentu yang disampaikan melalui bahasa dan lawan tutur akan berusaha menangkap arti dari pesan yang disampaikan. Sehingga, untuk menciptakan sebuah komunikasi yang baik, maka antara penutur dan lawan tutur harus saling memahami dengan baik. Namun, sering dijumpai bahwa maksud ujaran yang disampaikan oleh penutur tidak dapat difahami 
dengan baik oleh lawan tutur karena penutur menyampaikan pesannya dengan kurang jelas, ambigu, maupun tidak runtut.

Dalam ilmu linguistik dijelaskan bahwa komunikasi yang baik itu dapat dilakukan dengan mengikuti "Cooperative Principle" atau Prinsip Kerjasama yang disampaikan oleh Paul Grice. Prinsip kerjasama tersebut didefiniskan dengan "make your contribution such as is required, at the stage at which it occurs, by the accepted purpose or direction of the talk exchange in which you are engaged" ${ }^{1}$. Pada dasarnya prinsip kerjasama menjelaskan bahwa di dalam komunikasi setiap peserta tutur harus memberikan kontribusi dengan baik. kontribusi yang dimaksud adalah memberikan informasi yang cukup kepada lawan tutur, yaitu informasi yang benar, jelas, runtut, dan relevan dengan pembicaraan. Dalam prinsip ini, terdapat empat maksim yang harus diaplikasikan untuk menciptakan suatu komunikasi yang baik, yaitu maksim kualitas, maksim kuantitas, maksim relevansi, dan maksim cara.

Pada kenyataannya, di dalam komunikasi keempat maksim tersebut tidak selalu dipatuhi oleh para peserta tutur. Ketika maksim tidak diikuti atau dipatuhi dalam sebuah komunikasi, maka inilah yang disebut dengan "Flouting Maxim" atau Pelanggaran Maksim. Dalam bukunya, Jenny Thomas menyampaikan "when flouting a maxim, the speaker does not intend to mislead the hearer but wants the hearer to look for the conversational implicature, that is, the meaning of the utterance not directly stated in the words uttered. Therefore, when the speaker intentionally fails to observe a maxim the purpose may be to effectively communicate a message". ${ }^{2}$

Dari apa yang disampaikan oleh Thomas di atas, dapat disimpulkan bahwasanya ketika peserta tutur melanggar maksim dalam komunikasi, dia berharap agar lawan tuturnya dapat menangkap maksud dari perkataannya dimana pesan yang ingin ia sampaikan tidak dapat diutarakannya secara eksplisit. Hal ini karena ketika maksim itu dilanggar maka akan memunculkan implikatur atau sebuah makna tersembunyi dari suatu ujaran.

Ketika pelanggaran maksim terjadi di dalam suatu komunikasi, sebenarnya terdapat fungsi fungsi khusus yang ingin digunakan, seperti untuk menjaga hubungan baik antara

\footnotetext{
${ }^{1}$ Peter Grundy, Doing Pragmatics (London: Oxford University Press, Inc., 2000), 37.

2 Jenny Thomas, Meaning in Interaction: An Introduction to Pragmatics. (Harlow: Pearson Education, 2005)
} 


\section{Niswatin Nurul Hidayati}

penutur dan lawan tutur karena bahasa yaang digunakan akan menjadi lebih baik dan lebih sopan ketika melanggar maksim tersebut.

Kajian tentang pelanggaran maksim tersebut merupakan bagian dari kajian pragmatik. Secara sederhana pragmatik dapat didefinisikan sebagai studi yang berfokus pada makna ujaran yang disampaikan oleh penutur (penulis) dan diinterpretasikan oleh lawan tutur (pembaca) ${ }^{3}$. Hal ini karena ujaran yang disampaikan oleh seorang penutur bisa jadi mengindikasikan sesuatu yang lain yang tidak terlihat dengan jelas di dalam suatu tuturan. Pragmatik merupakan ilmu yang mengkaji tentang penggunaan bahasa dalam komunikasi. ${ }^{4}$ Sehingga, apa yang dikaji dalam pragmatik lebih cenderung pada apa yang penutur maksudkan dengan tuturannya, bukan semata-mata mengkaji tentang kata, frasa, ataupun klausa dalam suatu tuturan. Makna inilah yang kemudian disebut dengan implikatur. Untuk memahami tentang konsep implikatur, berikut adalah contoh dari ujaran yang mengandung implikatur:

\section{A : Tugas pragmatikmu udah selesai, Rin? \\ B : Deadline terjemahanku masih banyak banget.}

Pada contoh percakapan singkat diatas, terlihat bahwa jawaban yang diujarkan B tidak relevan dengan pertanyaan yang disampaikan A, sehingga jawaban ini tergolong dalam pelanggaran maksim yang disampaikan oleh Grice. Namun, ketika kita mencermati lebih lanjut, akan terlihat bahwa tuturan B mengandung implikatur untuk menjawab pertanyaan A. Tuturan B mengandung implikatur "aku belum mengenjakan tugas pragmatik karena deadline terjemahanku masih banyak. Setelah terjemahanku selesai, aku akan segera mengerjakannya"

Untuk memahami implikatur yang terkandung di dalam suatu ujaran, maka peserta tutur harus melihat kondisi yang ada disekelilingnya, baik kondisi fisik maupun kondisi sosial. Kondisi inilah yang disebut dengan konteks. Sehingga, dalam proses interpretasi atau penafsiran suatu ujaran, seseorang harus memperhatikan konteks yang ada disekelilingnya.

Dalam rangka melakukan penelitian terhadap pelanggaran maksim dalam suatu tutur di suatu percakapan, maka penulis menggunakan film sebagai salah satu cara untuk meneliti fenomena tersebut. Dalam penelitian ini, penulis menggunakan film pendek

\footnotetext{
${ }^{3}$ George Yule, Pragmatics (New York: Oxford University Press, 1996)

${ }^{4}$ Geoffrey Leech, Principles of Pragmatics (Cambridge: Cambridge University Press, 1983)
} 
dengan judul Radio Galau FM. Radio Galau FM merupakan film dengan genre romansa komedi yang cukup banyak diminati oleh kaula muda. Tuturan-turan yang terkandung dalam percakapan denggan tema semacam ini akan menarik untuk dianalisis, khususnya dari sisi pelanggaran maksim (flouting maxim), karena penuturnya cukup banyak menggunakan ujaran-ujaran tertentu yang mengandung makna implisit.

\section{B. Sinopsis}

Radio Galau FM merupakan film pendek yang diangkat dari novel karangan Bernard Batubara dengan judul yang sama. Film ini bertemakan cinta dan komedi yang berkisah tentang kehidupan anak muda. Terdapat tiga tokoh utama dalam film ini, yaitu Bara, Velin, dan Diandra. Ketiga tokoh tersebut merupakan siswa-siswi Sekolah Menengah Atas di Jakarta. Bara adalah siswa kelas XI yang selalu mendapatkan hinaan dari kakak perempuannya karena sudah tiga tahun tidak memiliki pacar. Sampai pada akhirnya, ada Velin yang tidak lain adalah adik tingkatnya di sekolah mengaguminya sejak lama karena melihat tulisan-tulisannya yang termuat di mading. Setelah keduanya berkenalan, hubungan keduanya semakin erat dan akhirnya keduanya saling Jatuh cinta. Bara dan Velin resmi menjadi sepasang kekasih. Satu bulan bersama, keduanya masih merasa nyaman satu sama lain dan tidak ada masalah serius yang datang. Masuk ke bulan kedua, sikap Velin menjadi sedikit berlebihan dan terlalu mendramatisir keadaan. Hal inilah yang membuat Bara merasa galau dengan pasangannya. Disaat itulah datang Diandra, seorang siswi kelas XII yang sangat cantik dan dikagumi. Pada akhirnya, Bara memutuskan untuk memutuskan Velin dan memilih Diandra sebagai pasangannya. Bara berfikir bahwa Diandra akan menjadi sosok pasangan yang diinginkannya, namun kenyatannya Diandra memiliki sifat yang lebih buruk, yaitu suka mengatur dan mendramatisir situasi.

\section{Landasan Teori}

Di dalam berkomunikasi, seseorang akan cenderung untuk lebih komunikatif sehingga pesan pesan yang akan disampaikan akan difahami oleh lawan bicara atau pendengar. Jacob L. Mey menyatakan bahwa "communication requires people to cooperate; the "bare facts" of conversation come alive only in a mutually accepted, pragmatically determined context". ${ }^{5}$ Dalam kajian ilmu linguistik, hal ini akan berkaitan erat dengan konsep "Cooperative Principle" atau prinsip kerjasama yang dikemukakan

\footnotetext{
${ }^{5}$ Jacob L. Mey, Pragmatics 2nd Edition (Australia: Blackwell Publishing, 2004)
} 
oleh H. Paul Grice dimana prinsip kerjasama ini menerapkan empat maksim didalamnya, yaitu maksim kualitas, maksim kuantitas, maksim relevansi, dan maksim pelaksanaan.

Prinsip kerjasama ini didefinisikan, "make your contribution such as is required, at the stage at which it occurs, by the accepted purpose or direction of the talk exchange in which you are engaged". ${ }^{6}$ Dari definisi prinsip kerjasama diatas, dapat dikemukakan bahwa baik pembicara ataupun pendengar harus saling memiliki keinginan untuk menyampaikan dan menginterpretasikan makna dari sebuah ujaran. Selain itu antara pembicara dan pendengar harus saling bekerja sama agar komunikasi itu berjalan dengan efisien. Seperti yang telah dikemukakan sebelumnya bahwa prinsip kerjasama yang dikemukakan oleh Grice terdiri dari empat maksim, sebagai berikut:

\section{a. Maksim Kuantitas}

Maksim kuantitas menyatakan bahwa seorang pembicara itu harus memberikan informasi atau kontribusi sesuai dengan kebutuhan dan tidak memberikan informasi yang lebih dari apa yang dipertanyakan atau dibutuhkan. Maka dari itu, dapat disimpulkan bahwasannya dalam maksim kuantitas, seorang pembicara atau penutur diharapkan memberikan informasi yang cukup, relatif memadai, dan seinformatif mungkin. Maka dari itu, jika seorang pembicara atau penutur memberikan informasi yang berlebihan dari apa yang di dibutuhkan oleh lawan bicara, ini berarti terjadi pelanggaran maksim.

Dalam bukunya, Peter Grundy memberikan contoh tentang maksim kuantitas sebagai berikut: ${ }^{7}$

A: Can you tell me what time it is?

B: it's 5 o'clock

Pada contoh diatas, dapat terlihat dengan jelas bahwa penutur "B" memberikan informasi yang memang dibutuhkan oleh " $A$ ", sehingga dalam hal ini "B" telah mentaati maksim kuantitas dalam prinsip kerjasama yang dikemukakan oleh Grice.

\section{b. Maksim Kualitas}

Maksim kualitas menjelaskan bahwa pembicaraatau penutur itu harus menyampaikan suatu hal sesuai dengan fakta dan seorang penutur tidak diperolehkan untuk memberikan informasi yang dia belum yakin apaka itu benar atau salah, atau

\footnotetext{
${ }^{6}$ Peter Grundy, Doing Pragmatics (London: Oxford University Press, Inc., 2000), 37.

${ }^{7}$ Peter Grundy, Doing Pragmatics (London: Oxford University Press, Inc., 2000)
} 
dalam hal ini dia tidak memiliki bukti yang cukup untuk menyampaikan suatu informasi. Grundy dalam bukunya juga memberikan contoh yang menarik yaitu "Pragmatics is difficult". Dalam hal ini, seorang penutur dapat mengatakan hal tersebut ketika dia pernah mengalami suatu hal yang membuatnya dapat mengatakan kalau mata kuliah Pragmatik itu sulit baginya, misalnya saja dia pernah mendapatkan nilai D untuk itu, tetapi jika dia belum pernah mengambil mata kuliah Pragmatik, dia tidak boleh mengatakan hal tersebut karena itu akan melanggar maksim kualitas.

\section{c. Maksim Relevansi}

Maksim relevansi memberikan penjelasan bahwasannya seorang pembicara atau penutur itu harus memberikan informasi yang relevan sehingga terjadi kerjasama yang baik antara pembicara dan pendengar dalam sebuah komunikasi. Untuk lebih jelasnya, berikut adalah contohnya:

A: Is there a doctor in the house?

B: I'm a doctor

Dalam pembicaraan diatas, dapat terlihat bahwasannya penutur "B" memberikan informasi yang relevan sehingga prinsip kerjasama dalam berjalan dengan baik antara keduanya dalam sebuah komunikasi.

\section{d. Maksim Cara}

Maksim pelaksanaan menyatakan bahwa seoran pembicara atau penutur itu harus memberikan informasi yang jelas, langsung serta menghindari hal hal atau informasi yang bersifat kabur atau ambigu. Grundy dalam bukunya memberikan contoh sebagai berikut:

A: I hear that you went to the theatre last night, what did you see?

B: I watch the drama performance.

Dalam pembicaraan diatas, dapat terlihat dengan jelas bahwa penutur " $\mathrm{B}$ " memberikan informasi yang jelas kepada "A" tentang pertanyaan apa yang dia tonton pada malam sebelumnya. Dalam hal ini dengan jelas "B" menuturkan kalau dia sedang melihat pertunjukan. Dengan demikian, dapat disimpulkan bahwa penutur "B" mentaati maksim pelaksanaan. 
Grice menekankan kembali pernyataannya tentang prisip kerjasama, bahwa: ${ }^{8}$ "...anyone who cares about the goals that are central to conversation/communication (such as giving and receiving information, influencing and being influenced by others) must be expected to have an interest, given suitable circumstances, in participation in talk exchanges that will be profitable only on the assumption that they are conducted in general accordance with the cooperative principle and the maxims"

Dari apa yang telah disampaikan oleh Grice dapat disimpulkan bahwa prinsip kerjasama harus diterapkan dalam komunikasi sehingga komunikasi tersebut akan berjalan lancar, jelas dan tidak membingungan. Tetapi, pada kenyataanya tidak semua prinsip dalam prisip kerjasama dapat di taati oleh penutur sehingga terjadinya pelanggaran maksim. Tetapi, tidak dapat pula dinyatakan bahwa pelanggaran maksim bukan pula sesuatu yang negatif karena seorang penutur akan mempunyai tujuan tertentu kenapa dia melakukan pelanggaran maksim, misalnya saja agar pernyataannya lebih sopan.

Jenny Thomas menyatakan bahwa ketika penutur melanggar suatu maksim atau prinsip kerjasama, dia tidak mengaharapkan sesuatu yang negatif, tetapi dia mengharapkan agar lawan bicaranya menangkan makna tersembunyi yang ada dalam ujarannya karena dia tidak dapat mengucapkannya secara langsung. Thomas juga menambahkan bahwasanya dengan cara seperti ini, ada kemungkinan bahwa teknik komunikasi seperti bisa dapat menjadi lebih efektif dalam penyampaian pesan. ${ }^{9}$

Ketika terjadi pelanggaran maksim di dalam suatu tuturan, maka akan menimbulkan suatu implikatur atau makna tersembunyi dari tuturan tersebut. Iplikatur percakapan adalah makna yang dipahami oleh peserta tuturan tetapi tidak dan kurang terungkap dalam apa yang diucapkan. ${ }^{10}$ Levinson dalam Nababan menjabarkan empat kegunaan konsep implikatur, yaitu: ${ }^{11}$

1. Konsep implikatur memungkinkan penjelasan fungsional yang bermakna atas fakta-fakta kebahasaan yang tidak terjangkau oleh teori linguistik

2. Konsep implikatur memberikan suatu penjelasan yang tegas/eksplisit tentang bagaimana mungkinnya bahwa apa yang diucapkannya secara lahiriah berbeda

\footnotetext{
${ }^{8}$ Grice, H.P. Studies in the Way of Words (Cambridge: Harvard University Press, 1989)

${ }^{9}$ Jenny Thomas, Meaning in Interaction: An Introduction to Pragmatics. (Harlow: Pearson Education, 2005)

${ }^{10}$ Harimurti Kridalaksana, Kamus Linguistik Edisi Keempat (Jakarta: PT. Gramedia Pustaka Utama, 2011)

${ }^{11}$ P. W. J. Nababan, Ilmu Pragmatik: Teori dan Penerapannya (Jakarta: Departemen Pendidikan dan Kebudayaan Direktorat Jenderal Pendidikan Tinggi Proyek Pengembangan Lembaga Pendidikan Tenaga Kependidikan, 1987)
} 
dari apa yang dimaksud dan bahwa pemakai bahasa itu mengerti (menangkap) pesan yang dimaksud

3. Konsep implikatur dapat menyederhanakan pemerian semantik dari perbedaan hubungan antar klausa, walaupun klausa-klausa itu dihubungkan dengan kata-kata struktur yang sama.

4. Beberapa butir dasar-dasar implikatur dapat menerangkan berbagai macam fakta/gejala secara lahirian kelihatan tidak berkaitan dan/atau berlawanan (seperti metafora)

Sehingga, untuk memahami suatu implikatur dari suatu ujaran, maka seseorang harus melihat konteks dari tuturan tersebut. Dalam menginterpretasikan sutau implikatur, penutur tidak dapat melepaskan konteks percakapan yang mencakup topik percakapan, peserta percakapan, dan latar belakang percakapan. ${ }^{12}$

Konteks dalam suatu percakapan adalah segala latar belakang pengetahuan yang dimiliki oleh penutur, mitra tutur dan yang menyertai dan mewadahi pertuturan tertentu. ${ }^{13}$ Konteks dalam suatu tuturan dapat berupa aspek fisik maupun aspek sosial yang diketahui oleh penutur dan lawan tuturnya. Sedangkan Hymes (dalam Wardhaugh, 1986) menyebutkan delapan komponen tutur yang mempengaruhi pilihan tutur sesorang, yaitu setting atau scene (tempat dan waktu, participants (peserta tindak tutur), ends (tujuan yang hendak dicapai oleh peserta tutur), act of sequences (bentuk atau isi sesuatu yang dibicarakan, kata-kata yang diucapkan dan bagaimana hubungannya dengan topik yang dibicarakan), key (nada suara, keadaan emosional pembicara), instrumentalities (media yang digunakan), norms (norma kebahasaan yang dianut oleh suatu masyarakat bahasa) dan genres (tipe wacana). Komponenkomponen tersebut diringkas menjadi speaking. ${ }^{14}$

Sehingga, dapat ditarik kesimpulan bahwa adanya pelanggaran maksim dalam suatu tuturan akan memunculkan adanya makna tersembunyi atau implikatur dari tuturan tersebut. Kemudian, untuk melakukan analisis terhadap implikatur tersebut, sebaiknya kita melihat konteks yang ada disekitar tuturan tersebut.

\section{Metode Penelitian}

Di dalam penelitian ini, objek yang digunakan adalah tuturan dari tiga tokoh utama dalam film Radio Galau FM. Penelitian ini memiliki tujuan untuk menjelaskan tentang

\footnotetext{
${ }^{12}$ F.X. Nadar, Pragmatik \& Penelitian Pragmatik (Yogyakarta: Graha Ilmu, 2009)

${ }^{13}$ Kunjana Rahardi, Pragmatik Kesantunan Imperatif Bahasa Indonesia (Yogyakarta: Erlangga, 2005)

${ }^{14}$ Ronald Wardhaugh, An Introduction to Sociolinguistics (Oxford: Basil Blackwell, 1986)
} 
maksim-maksim yang dilanggar oleh ketiga tokoh utama tersebut. disamping itu, penulis juga akan mendeskripsikan bagaimana maksim tersebut dilanggar, serta implikatur yang timbul sebagai akibat dari pelanggaran maksim tersebut. Sehingga, metode yang digunakan dalam penelitian ini adalah deskriptif kualitatif.

Data yang akan dianalisis dalam penelitian ini merupakan data lisan yang didapatkan dari tuturan tiga tokoh utama dari film Radio Galau FM. Seluruh percakapan dalam film disimak oleh peneliti untuk melihat tuturan atau percakapan mana sajakah yang mengandung pelanggaran maksim. Sehingga, di dalam proses penyediaan data, metode simak adalah metode yang tepat digunakan dalam penelitian ini.

Penulis menggunkana metode padan pragmatis untuk melakukan analisis data. Di dalam proses melakukan analisis terhadap data yang telah terkumpul, maka peneliti akan mengklasifikasikan pelanggaran maksim yang ditemukan ke dalam empat macam pelanggaran maksim, yaitu pelanggaran maksim kuantitas, kualitas, relevansi, dan cara. Maksim-maksim ini sesuai dengan yang sebutkan oleh Grice dalam prinsip kerjasama yang telah dijelaskan pada bab sebelumnya. Kemudian, peneliti akan melihat pola atau bagaimana pelanggaran maksim yang di temukan dalam tuturan tiga tokoh utama dalam film Radio Galau FM. Setelah itu, penulis akan mencoba mendeskripkan implikatur apa atau tujuan apa yang terkandung dari maksim-maksim yang dilanggar.

\section{E. Pelanggaran Maksim dalam Tuturan Tokoh Utama Film Radio Galau FM}

Di dalam film Radio Galau FM ini, terdapat beberapa pelanggaran maksim yang terkandung di dalam ujaran-ujaran tiga tokoh utama di dalam film ini, yaitu Bara, Velin, dan Diandra.

\section{a. Pelanggaran Maksim Kuantitas}

Pelanggaran maksim kuantitas dapat terjadi ketika penutur memberikan informasi yang lebih dari apa yang dibutuhkan oleh lawan bicara atau pendengarnya.

\section{Percakapan 1}

Velin

Diandra

Velin

Diandra

Velin
: Kak Diandra..

: Iya..

: Aku boleh nanya nggak kak? Kak Di tau kan kalo Bara itu pacar aku?

: Lo gak usah ingetin gue deh. Lo itu bukan alarm handphone gue.

: Kalo gitu, kakak bisa nggak jauhin Bara? 
Diandra : Lo bisa nggak putusin Bara? Velin, lo tau kan Bara itu udah gak tahan pacaran sama lo?

Velin

Diandra

: Tapi, Bara masih sayang sama aku kok kak?

\section{Diandra}

: Tapi dia juga sayang sama gue. Bara itu.. udah gak sayang sama lo. Dia lebih sayang sama gue. Lo itu cuman anak kecil yang manja yang kerjaannya selalu ngrepotin Bara. Dan lo tau nggak, Bara itu

Velin udah muak banget liat kelakuan lo.

Diandra

: Tapi...

: apa lagi?

Percakapan 1 diatas terjadi antara tokoh Velin dan Diandra. Kedua gadis tersebut sedang dekat laki-laki yang sama, yaitu Bara. Pada dasarnya, Bara telah menyatakan keinginannya untuk mengakhiri hubungannya dengan Velin, namun Velin menolak permintaan tersebut. Karena itu, Bara berusaha untuk mendekati gadis lain untuk melancarkan niatnya mengakhiri hubungannya dengan Velin. Velin mengetahui rencana tersebut dan akhirnya dia datang menemui diandra.

Pada percakapan diatas, terlihat bahwa Velin meminta Diandra untuk menjauhi kekasihnya, karena ia merasa bahwa statusnya masih sebagai kekasih Bara. Namun, Diandra menolak untuk memenuhi permintaan Velin dan menyatakan kalau Bara sudah tidak menyayanginya lagi. Velin masih membela diri dengan menyatakan “Tapi, Bara masih sayang sama aku kok kak?". Kemudian, Diandra membalasnya dengan berkata "Tapi dia juga sayang sama gue. Bara itu.. udah gak sayang sama lo. Dia lebih sayang sama gue. Lo itu cuman anak kecil yang manja yang kerjaannya selalu ngrepotin Bara. Dan loe tau nggak, Bara itu udah muak banget liat kelakuan lo."

Dari ujaran yang disampaikan oleh Diandra tersebut, terlihat adanya pelanggaran maksim yang terjadi. Hal ini karena Diandra memberikan informasi yang berlebihan dan informasi tersebut tidak pernah diminta oleh lawan tuturnya. Ketika velin berkata “Tapi, Bara masih sayang sama aku kok kak?”, pada dasarnya ia cukup membalasnya dengan berkata "Bara itu.. udah gak sayang sama lo.". Namun,Diandra memaparkan pula argumennya bahwa alasan Bara sudah tidak menyayangi Velin lagi adalah karena ia manja dan selalu merepotkannya. Terlebih lagi ia beranggapan bahwa Bara sudah tidak menginginkan untuk melihat Velin lagi. Tambahan informasi yang berlebihan ini disebut dengan pelanggaran maksim kuantitas. 
Dari pemaparan yang panjang tersebut, terlihat bahwa Diandra memiliki tujuan untuk meyakinkan Velin bahwa Bara sudah tidak menginginkannya lagi. Itulah mengapa ia memberikan jawaban yang Diandra anggap dapat menjadi bukti bahwa sudah tidak menginginkan untuk bersama Velin lagi.

\section{b. PelanggaranMaksim Kualitas}

Pada dasarnya pelanggaran maksim kualitas adalah ketika seorang penutur tidak memberikan informasi yang sesuai dengan kenyataan dan dalam hal ini seorang penutur menghindari "going on record" atau pernyataan secara langsung.

\section{Percakapan 2}

Bara $\quad$ : Vel.. eee.. nanti malem kamu ada acara nggak?

Velin : Mmm.. gak ada.

Bara : Aku mau ajak kamu pergi.

Velin : Kemana?

Bara $\quad$ Pokoknya nanti aku jemput jam 7 aja. Oke? Janji?

Velin

: Janji.

Percakapan diatas terjadi diantara tokoh Bara dan Velin. Konteks yang tergambar adalah bahwa Bara menanyakan agenda Velin pada malam hari karena iaberencana untuk mengajaknya pergi. Karena Bara tidak memberitahukan kemana mereka akan pergi, Velin bertanya kepadanya dengan mengucapkan “Kemana?". Untuk memenuhi prinsip kerjasama yang dikemukakan oleh Grice, Bara seharusnya memberikan jawaban dengan menyebutkan tempat tujuan mereka pada malam tersebut, misalnya restoran, mal, bioskop, dan lain-lain. Namun, Bara menjawabnya dengan menucapkan "Pokoknya nanti aku jemput jam 7 aja. Oke? Janji?". Dengan memberikan jawaban tersebut, penulis menyimpulkan bahwa tuturan Bara melanggar maksim kualitas. Hal ini karena Bara tidak memberikan jawaban yang sebenarnya dari pertanyaan tersebut. Tentu, pelanggaran maksim yang terdapat dalam tuturan tersebut menganduk makna tertentu atau implikatur.

Ketika melihat konteks dari percakapan antara Bara dan Velin diatas, maka dapat disimpulkan bahwa tuturan Bara mengandung implikatur berupamaksud untuk memberikan kejutan pada Velin dengan tidak memberitahukan kemana tujuan mereka pergi. Ketika percakapan tersebut terjadi, hubungan antara kedua tokoh tersebut sangat dekat. Sehingga, dari konteks yang ada tersebut dapat diinterpretasikan bahwa 
Bara akan mengungkapkan isi hatinya kepada Velin dengan mengajaknya untuk pergi bersama.

\section{c. Pelanggaran Maksim Relevansi}

Seperti yang telah dijelaskan pada bagian terdahulu bahwa dalam maksim relevansi, seorang penutur harus memberikan informasi yang relevan. Kemudian, ketika hal tersebut dilanggar, maka akan terjadi pelanggaran maksim relevansi.

$\begin{array}{lll}\text { Bara } & : \text { Loh.. kok lo ada disini? } \\ \text { Diandra } & : \text { Kenapa? Mau bilang ini tempat lo? Terus gue gak boleh disini? } \\ \text { Bara } & : \text { Enggak.. ini kan tempat umum. Banyak kok orang yang datang kesini. } \\ \text { Diandra } & : \text { Kenapa? Mau ngatain bacaan gue norak? Kayak anak kecil? } \\ \text { Bara } & : \text { Enggak.. nggak.. Enggak.. ya gue gak nyangka aja cewek galak kayak } \\ & \text { lo bacaannya buku teenlit kayak gitu. } \\ \text { Diandra } & : \text { Lo itu baru kenal sama gue, tapi lo udah ngatain gue dua kali ya } \\ \text { Bara } & : \text { Eng..gaak. } \\ \text { Diandra } & : & \text { Barusan? Lo ngatain gue galak dan secara gak langsung lo juga } \\ \text { Bara } & : & \frac{\text { Gdah nyindir selera baca gue. }}{\text { Gue Bara. Gue udah dua kali loh ngajakin lo kenalan dan kalo }} \\ & & \frac{\text { sampai saat ini lo masih nolak juga, lo dosa loh. Di agama itu }}{\text { dijelasin kalo menjalin tali silaturrahim diantara umat beragama }} \\ & : & \frac{\text { Ytu hukumnya wajib. Dosa kalo menolaknya. }}{\text { Yaahh.. gue diandra. Panggil aja Di. }}\end{array}$

Tokoh yang terlibat dalam percakapan diatas adalah Bara dan Diandra. Diandra merupakan kakak tingkat Bara yang pertama kali ia temui di taman sekolah meskipun keduanya belum berkenalan pada saat itu. Kemudian, pertemuan kedua mereka adalah di toko buku. Bara terkejut ketika bertemu dengannya di toko tersebut sehingga ia menyapa Diandra dengan berkata “Loh.. kok lo ada disini?". Diandra merasa sedikit tersinggung karena ia merasa Bara tidak memperbolehkannya untuk berada disana. Kemudian, Bara menjelaskan kepadanya kalau toko buku tersebut adalah tempat umum sehingga setiap orang boleh pergi ke tempat tersebut. Sesaat setelah itu, Bara melihat buku yang dibaca Diandra adalah novel teenlit dan ia berkomentar bahwa ia tidak menyangka Diandra menyukai novel semacam itu.

Diandra merasa tersinggung dan berkata "Barusan? Lo ngatain gue galak dan secara gak langsung lo juga udah nyindir selera baca gue.”. Sebenarnya, Bara tidak bermaksud untuk menyinggung perasaan Diandra seperti itu, namun ia bingung untuk mengatakan sesuatu. Akhirnya, ia membalas pernyataan Diandra tersebut dengan 
mengajaknya berkenalan dengan mengatakan "Gue Bara. Gue udah dua kali loh ngajakin lo kenalan dan kalo sampai saat ini lo masih nolak juga, lo dosa loh. Di agama itu dijelasin kalo menjalin tali silaturrahim diantara umat beragama itu hukumnya wajib. Dosa kalo menolaknya.”. Jawaban yang diberikan oleh Bara kepada lawan tuturnya tersebut termasuk di dalam golongan pelanggaran maksim relevansi. Hal ini karena apa yang diujarkan oleh Bara tidak relevan dengan pernyataan Diandra yang beranggapan bahwa Bara telah menyindir selera bacanya. Namun kemudian Bara malah mengajaknya berkenalan dan menjelaskan bahwa saat itu adalah kedua kalinya ia mengajak Diandra berkenalan.

Dengan melakukan pelanggaran terhadap maksim relevansi tersebut, terdapat implikatur atau makna tersembunyi yang terkandung dalam ujaran Bara. Makna tersebut berupa tujuan dari Bara untuk menghindari konflik yang memungkinkan untuk terjadi ketika keduanya terus membahas tentang selera buku yang dibaca oleh Diandra. Sehingga, Bara mencoba mengalihkan arah pembicaraan mereka dengan mengajak Diandra berkenalan.

\section{d. Pelanggaran Maksim Cara}

Pelanggaran maksim pelaksanaan akan terjadi ketika seorang penutur atau pembicara memberikan informasi yang ambigu dan tidak jelas.

Bara : Kamu kenapa vel?

Velin : Gak papa.

Bara : Mmmm..

Velin : Udah..gitu doang? Kamu gak pengen tau gitu aku kenapa?

Bara : Tadi katanya kamu gak kenapa-kenapa?

Velin : iihh.. kamu nyebelin banget ya. Kalo aku jawabnya gak kenapakenapa itu artinya aku kenapa-kenapa, Bar. Kamu gak sensitif banget sih jadi cowok. Yang peka dong! Eehh.. diem lagi.. kamu hibur aku dong Bar.. kamu bukannya bikin aku seneng malah bikin aku tambah bete ya.. hibur gitu kek, nyanyi kek, nari kek, becandain aku kek..

Bara : Ini...

Velin : Bara...! aku itu gak laper!! Nyebelin banget sih.. kenapa gak dimakan?

Tokoh yang terlibat dalam percakapan diatas adalah Bara dan Velin. Mereka telah meresmikan hubungan mereka satu bulan yang lalu. Selama bulan pertama, hubungan mereka berjalan lancar dan tanpa konflik.Pada saat percakapan diatas 
terjadi, hubungan mereka telah masuk ke bulan kedua dimana beberapa konflik mulai terjadi diantara mereka. Pada percakapan diatas, Bara melihat wajah Velin yang terlihat murung, sehingga ia menanyakan alasan mengapa Velin seperti itu. Namun, kemudian Velin hanya menjawabnya dengan mengucapkan "Gak papa" sehingga Bara tidak memberikan respon lagi kepadanya. Lalu, Velin menjawabnya dengan nada kesal dengan mengatakan "Udah..gitu doang? Kamu gak pengen tau gitu aku kenapa?". Karena Bara semakin bingung dengan apa yang dikatakan kekasihnya, ia bertanya “Tadi katanya kamu gak kenapa-kenapa?”. Mendengar bertanya seperti itu, menjawabnya dengan mengatakan "iihh. kamu nyebelin banget ya. Kalo aku jawabnya gak kenapa-kenapa itu artinya aku kenapa-kenapa, Bar. Kamu gak sensitif banget sih jadi cowok. Yang peka dong! Eehh.. diem lagi.. kamu hibur aku dong Bar.. kamu bukannya bikin aku seneng malah bikin aku tambah bete ya.. hibur gitu kek, nyanyi kek, nari kek, becandain aku kek.."

Ketika melihat jawaban dari Velin tersebut, penulis melihat bahwa jawaban yang diujarkan Velin terkesan berputar-putar, tidak jelas, dan ambigu. Sehingga, Bara tidak mengerti dengan apa yang diujarkannya. Sehingga, tuturan Velin tersebut tergolong dalam pelanggaran maksim cara. Ketika Bara melakukan konfirmasi dengan mengatakan “Tadi katanya kamu gak kenapa-kenapa?”, Velin menjawabnya dengan mengatakan kalau Bara adalah orang yang menyebalkan, tidak sensitif, dan tidak peka. Padahal, apa yang sebenarnya ingin dikatakan oleh Velin kepadanya adalah sebenarnya ia sedang memiliki masalah. Namun, ia menjelaskannya dengan tidak jelas. Inilah yang disebut dengan pelanggaran maksim cara.

Pelanggara maksim yang terkandung dalam ujaran Velin tersebut mengandung makna tersembunyi atau implikatur. Dari konteks yang ada pada percakapan diatas, penulis dapat menyimpulkan bahwa apa yang ingin Velin sampaikan sebenarnya adalah bahwa ia sedang memiliki masalah dan berharap bahwa Bara akan menghiburnya. Namun, ia tidak menyatakanya secara eksplisit sehingga Bara tidak mengerti apa yang dimaksud oleh Velin.

\section{F. Penutup}

Grice menyatakan bahwa untuk dapat melakukan komunikasi yang baik, seorang penutur dan lawan tutur harus mematuhi prinsip kerja sama (cooperative principle) yang terdiri dari empat maksim, yaitu maksim kuantitas, maksim kualitas, maksim relevansi, 


\section{Niswatin Nurul Hidayati}

dan maksim cara. Namun, di dalam kehidupan sehari-hari, prinsip kerjasama tersebut ternyata tidak selalu dipatuhi oleh pengguna bahasa. Sering ditemukan adanya pelanggaran maksim (flouting maxim) dimana seorang penutur memiliki maksud tertentu dengan tuturannya yang seperti itu. Film sebagai salah satu representasi kehidupan masyarakat menjadi objek yang cukup baik untuk melakukan analisis terhadap pelanggaran maksim. Film Radio Galau FM diatas menunjukkan bahwapelanggaran maksim dalam komunikasi memang terjadi.

Dari analisis yang telah dilakukan diatas, penulis menemukan beberapa percakapan yang mengadung pelanggaran maksim, yaitu pelanggaran maksim kuantitas, kualitas, relevansi, dan cara. Ketika pelanggaran maksim terjadi, terdapat makna tersembunyi yang terkandung berupa maksud sebenarnya yang akan ia sampaikan. Misalnya, dari analisis pelanggaran maksim pada ujaran tokoh-tokoh utama fil Radio Galau FM diatas terdapat beberapa implikatur yang terkandung, misalnya meyakinkan lawan tutur, memberikan kejutan, menginginkan perhatian, serta menghindari konflik.

\section{Daftar Pustaka}

Grice, H.P. 1989. Studies in the Way of Words. Cambridge: Harvard University Press.

Grundy, Peter. 2000. Doing Pragmatics. London: Oxford University Press, Inc.

Kridalaksana, Harimurti. 2011. Kamus Linguistik Edisi Keempat. Jakarta: PT. Gramedia Pustaka Utama

Leech, Geoffrey. 1983. Principles of Pragmatics. Cambridge: Cambridge University Press.

Mey, Jacob L., 2004. Pragmatics 2nd Edition. Australia: Blackwell Publishing

Nababan, P. W. J. 1987. Ilmu Pragmatik: Teori dan Penerapannya. Jakarta: Departemen Pendidikan dan Kebudayaan Direktorat Jenderal Pendidikan Tinggi Proyek Pengembangan Lembaga Pendidikan Tenaga Kependidikan.

Nadar, F.X. 2009. Pragmatik \& Penelitian Pragmatik. Yogyakarta: Graha Ilmu.

Rahardi, Kunjana. 2005. Pragmatik Kesantunan Imperatif Bahasa Indonesia. Yogyakarta: Erlangga.

Thomas, Jenny. 1995. Meaning in Interaction: An Introduction to Pragmatics. Harlow: Pearson Education. 
Pelanggaran Maksim

Yule, George. 1996. Pragmatics. New York: Oxford University Press.

Wardhaugh, Ronald. 1986. An Introduction to Sociolinguistics. Oxford: Basil Blackwell. 